\title{
EFECTO DE LA UTILIZACIÓN DEL SUERO LÍQUIDO DE LECHE, CON O SIN ADICIÓN DE AMONIO CUATERNARIO, COMO SUSTITUTO DEL AGUA DE BEBIDA EN EL RENDIMIENTO PRODUCTIVO DE GALLINAS PONEDORAS
}

\author{
EFFECT OF LIQUID WHEY, WITH OR WITHOUT QUATERNARY AMMONIUM, AS A \\ SUBSTITUTE OF DRINKING WATER ON PERFORMANCE OF LAYING HENS
}

${ }^{1}$ Marcial Estanislao Cumpa Gavidia y ${ }^{2}$ Ricardo Ronal Postigo Armaza

\begin{abstract}
Resumen
El objetivo del presente estudio fue evaluar la utilización del suero líquido de leche, con o sin adición de amonio cuaternario, como sustituto del agua de bebida en gallinas ponedoras a través del comportamiento productivo y retribución económica del alimento. Para ello, se utilizaron 162 gallinas Hy-Line Brown, distribuidas al azar en tres grupos de 54 aves cada uno y fueron alimentadas por 56 días. Los tratamientos fueron: T1, agua + amonio cuaternario; T2, Suero de Leche y T3, Suero de Leche + amonio cuaternario. Los resultados mostraron que los tratamientos con suero líquido de leche (T2 y T3) tuvieron significativamente mayor producción de huevos, mayor masa de huevos, menor consumo de alimentos, mayor consumo de líquidos y mejor conversión alimenticia que el tratamiento 1. En calidad del huevo, no hubo diferencias significativas en peso específico, calidad de albumen y pigmentación de la yema entre los 3 tratamientos. La retribución económica fue favorable al grupo suplementado con suero de leche (T2). En conclusión, la administración de suero líquido de leche mejora el comportamiento productivo en gallinas ponedoras. causas más frecuentes en ambos tipos de incubación fueron las anormalidades viscerales y desordenes circulatorios.
\end{abstract}

Palabras clave: Suero de leche, gallinas ponedoras, comportamiento productivo.

\begin{abstract}
The objective of the present study was to evaluate the effect of the use of liquid whey, with or without quaternary ammonium, as a substitute for drinking water in laying hens as measured by performance and profitability. $162 \mathrm{Hy}-$ Line Brown hens were randomly and equally allocated to three groups of 54 birds each and were fed for 56 days. The treatments were: T1, drinking water + quaternary ammonium, T2, whey and T3, whey + quaternary ammonium. Results showed that treatments with whey (T2 and T3) had significantly higher egg production, greater egg mass, lower feed consumption, higher liquid consumption and lower feed conversion than treatment 1 . No significant differences were observed in egg quality (specific weight, albumen quality and yolk pigmentation) among these treatments. The margin over feed was higher for the group supplemented with liquid whey (T2). In conclusion, administration of liquid whey improve performance in laying hens. The objective of the present study was to evaluate the effect of the use of liquid whey, with or without quaternary ammonium, as a substitute for drinking water in laying hens as measured by performance and profitability. $162 \mathrm{Hy}$-Line Brown hens were randomly and equally allocated to three groups of 54 birds each and were fed for 56 days. The treatments were: T1, drinking water + quaternary ammonium, T2, whey and $\mathrm{T} 3$, whey + quaternary ammonium. Results showed that treatments with whey (T2 and T3) had significantly higher egg production, greater egg mass, lower feed consumption, higher liquid consumption and lower feed conversion than treatment 1 . No significant differences were observed in egg quality (specific weight, albumen quality and yolk pigmentation) among these treatments. The margin over feed was higher for the group supplemented with liquid whey (T2). In conclusion, administration of liquid whey improve performance in laying hens.
\end{abstract}

Keys words: Whey, laying hens, performance.

\footnotetext{
${ }^{1}$ Departamento Producción Animal Facultad de Zootecnia UNALM. E-mail: mcumpa@lamolina.edu.pe ${ }^{2}$ Ingeniero Zootecnista

${ }^{2}$ Departamento Producción Animal Facultad de Zootecnia UNALM. E-mail: mcumpa@lamolina.edu.pe ${ }^{2}$ Ingeniero Zootecnista
} 


\section{Introducción}

El suero de leche se obtiene después de la separación de la cuajada en la fabricación del queso, contiene proteínas séricas, lactosa y muchos de los minerales y vitaminas de la leche original (Porter, 1981). Este sub producto tiene una alta demanda biológica de oxígeno y su eliminación en los ríos destruye organismos vivos; por lo tanto, un aprovechamiento de este recurso como insumo alimenticio contribuiría a reducir la contaminación ambiental. El suero de leche retiene cerca del $55 \%$ de los nutrientes de la leche, tiene 6.35 a $6.50 \%$ de materia seca, 4.90 $\%$ de lactosa, $0.80 \%$ de proteína, 0.04 a $0.50 \%$ de grasa, 0.05 a $0.40 \%$ de ácido láctico y 0.50 a $0.80 \%$ de cenizas (Kosikowski, 1979). Entre las proteínas de este insumo tenemos $\beta$-lactoglobulina, ó-lactoalbúmina, albúmina de suero bovino, IgG, lactoferrina, lactoperoxidasa y la fracción proteasa peptona (De Wit, 1998). Los aminoácidos esenciales del suero son: metionina $1.8 \%$, lisina $8.8 \%$, triptófano $24 \%$, treonina $6.8 \%$, entre otros (Glass y Hedrick, 1977). Valencia y Ramirez (2009) indican que en el año 2007, había una producción de 145 millones de toneladas de suero de leche, siendo este recurso mayormente desperdiciado. Kermanshahi y Rostami (2006) mencionan que el uso de prebióticos, en lugar de antibióticos, se está popularizando en aves, para mejorar la población microbiana del tracto gastrointestinal. La lactosa que es el mayor componente del suero de leche, es un prebiótico, dado que las aves al no tener lactasa no pueden digerir la lactosa y esta llega casi intacta a los ciegos y al intestino grueso (Torres-Rodriguez et al., 2007). Si no se conserva adecuadamente, el suero de leche se vuelve acido puesto que contiene microorganismos lácticos, por tanto es indispensable, someterlo a un pretratamiento, de enfriamiento o la adición de compuestos antimicrobianos (Varnan y Sutherland, 1996). El amonio cuaternario es un biocida que agregado al alimento, permitiría una conservación integral del producto con todas sus características de cantidad, calidad y pureza (Ribas, 2010). El amonio cuaternario actúa ingresando a través de la membrana celular de los microorganismos causando desnaturalización e inactivación de proteína esenciales presentes en el citoplasma; así como también puede alterar el mecanismo de transporte activo del nitrógeno y el fosforo a través de la membrana (Molina et al., 2013). Trauth et al. (2001) reportaron que el amonio cuaternario reduce la actividad de fermentación de las bacterias productoras de ácido láctico, inhibiendo el crecimiento bacterial y la acidificación. Asimismo, este biocida se emplea para potabilizar el agua, manteniéndola fresca, limpia, con olor y sabor agradables. Espinoza (1993) encontró mayores ganancias de peso en pavos a la octava semana de edad utilizando amonio cuaternario como biocida del suero de leche, comparado con el suero sin desinfectante. Vega (1995) utilizando suero líquido de leche en reemplazo de agua de bebida, con y sin adición de un yodóforo, encontró en pavos de carne que la ingestión del suero de leche redujo el consumo de alimento en $11.25 \%$ y mejoró la eficiencia alimenticia en
$10.06 \%$. El uso de suero de leche deshidratado en dietas de pollos de carne permitió obtener mayores ganancias de peso pesos corporales en comparación con los tratamientos sin adición de suero (Torki y Molanapour, 2005; Kermanshahi y Rostami, 2006). El presente estudio tuvo como objetivo evaluar el efecto de la utilización del suero liquido de leche, con y sin adición de amonio cuaternario, como sustituto del agua de bebida en el rendimiento productivo de las gallinas ponedoras medido a través de producción de huevos, masa de huevos, consumo de alimentos, ingestión de líquidos (suero de leche y agua), conversión alimenticia, calidad del huevo (peso específico, calidad de albumen y pigmentación de yema) y retribución económica.

\section{Materiales y métodos}

El presente estudio se realizó en las instalaciones de la Unidad Experimental de Avicultura de la Universidad Nacional Agraria La Molina, y tuvo una duración de 56 días. Se utilizaron 162 gallinas Hy-Line Brown de 40 semanas de edad seleccionadas aleatoriamente, que fueron alojadas en 54 jaulas, en cada una se colocaron 3 gallinas. Cada grupo (54 aves) recibió uno de los siguientes tratamientos: T1, agua + amonio cuaternario; T2, suero líquido de leche y T3, suero líquido de leche + amonio cuaternario. El amonio cuaternario se empleó en un nivel de $0.2 \mathrm{ml}$. por 1 litro de agua o suero. Se empleó una misma dieta para todos los tratamientos y esta fue formulada en base a los requerimientos nutricionales de la línea correspondientes a la etapa de postura. La composición y el valor nutricional calculado se aprecia en la Tabla 1.

Tabla 1. Composición porcentual del alimento y valor nutricional calculado.

\begin{tabular}{cc}
\hline Insumos (\%) & Dieta Basal \\
\hline Maíz, grano amarillo & 65.30 \\
Torta de Soya & 15.14 \\
Carbonato de calcio & 8.74 \\
Afrecho de trigo & 5.00 \\
Harina de Pescado & 4.87 \\
Fosfato dicálcico & 0.30 \\
Sal común & 0.25 \\
Aceite de pescado & 0.13 \\
DL- Metionina & 0.10 \\
Mezcla de Vitaminas y Minerales & 0.10 \\
Promotor de crecimiento & 0.05 \\
Cloruro de colina 60\% & 0.02 \\
Total & 100.00 \\
Nutrientes (Calculado) & \\
Materia Seca, \% & 91.00 \\
Proteína Total & 16.90 \\
Lisina, \% & 2.85 \\
Metionina, \% & 0.86 \\
Metionina - Cistina, \% & 0.41 \\
Fósforo Disponible, \% & 0.65 \\
Calcio, \% & 0.28 \\
Sodio, \% & 3.60 \\
\hline
\end{tabular}


El suero líquido de leche empleado para el presente estudio fue proporcionado diariamente por la Planta de Leche de la Universidad Nacional Agraria La Molina y cuyo análisis químico se observa en la Tabla 2.

Tabla 2. Composición Química del Suero Líquido de Leche.

\begin{tabular}{cc}
\hline Componente & Porcentaje \\
\hline Agua & 93.50 \\
Sólidos & 6.50 \\
Lactosa & 5.00 \\
Proteína & 0.60 \\
Grasa & 0.30 \\
Cenizas & 0.62 \\
Sal & 0.14 \\
Fósforo & 0.76 \\
Calcio & 0.97 \\
Metionina & 0.19 \\
\hline
\end{tabular}

Análisis realizado por el Laboratorio de Industrias Alimentarias de la UNALM (Vega, 1995).

Las mediciones realizadas fueron la producción de huevos, masa de huevos, consumo de alimento, ingestión de líquido, conversión alimenticia y retribución económica. Se evalúo el espesor de cáscara (peso específico del huevo), calidad interna del huevo (Unidades Haugh) y pigmentación de yema (unidades) y retribución económica del alimento. El estudio se realizó mediante el Diseño completamente al azar, con tres tratamientos y tres repeticiones por tratamiento. Los datos obtenidos fueron sometidos a análisis de varianza usando el programa estadístico Statistical Analysis System (SAS). Para la comparación de medias se utilizó la prueba de Duncan.

\section{Resultados y discusión}

Los efectos de la utilización del suero de leche en reemplazo del agua de bebida se presentan en la Tabla 3. En porcentaje de postura, se observaron diferencias significativas a favor de las gallinas con suministro de suero de leche. En general, las aves de los tratamientos con suero de leche tuvieron una producción de huevos significativamente mayor en comparación con las aves que recibieron solo agua de bebida más amonio cuaternario. Esto estaría relacionado probablemente a la mayor ingestión de proteínas (Tabla 4) de alta calidad como la lactoalbúmina y la lactoglobulina. Igualmente, los tratamientos con suero de leche (suero y suero más desinfectante) produjeron significativamente una mayor masa de huevo en comparación con el tratamiento de agua de bebida. También pudo deberse a que la lactosa, principal componente del suero de leche, actuó como prebiótico a nivel de ciegos e intestino grueso. La lactosa estimula el crecimiento y la actividad de bacterias beneficiosas para la flora intestinal, coincidente con lo reportado por Torki y Molanopour (2005), Kermanshahi y Rostami (2006) y Torres-Rodriguez et al. (2007) quienes reportan mejoras significativas en aves con el uso de la lactosa como prebiótico.

Las gallinas que recibieron suero de leche más amonio cuaternario no difieren de las aves que solo recibieron suero de leche, en relación a la postura y masa de huevos, de modo que no hubo mejoras con la adición del amonio cuaternario al suero de leche.

Tabla 3. Efecto de la utilización del suero líquido de leche en reemplazo del agua de bebida sobre los parámetros productivos y retribución económica.

\begin{tabular}{lccc}
\hline \multicolumn{1}{c}{ Parámetros } & $\begin{array}{c}\text { T-1: Agua } \\
\text { + Amonio } \\
\text { Cuaternario }\end{array}$ & $\begin{array}{c}\text { T-2: Suero de } \\
\text { Leche }\end{array}$ & $\begin{array}{c}\text { T-3: Suero de } \\
\text { Leche + Amonio } \\
\text { Cuaternario }\end{array}$ \\
\hline Producción de huevos (\%) & $73.56^{\mathrm{b}}$ & $79.68^{\mathrm{a}}$ & $79.89^{\mathrm{a}}$ \\
Masa de huevos (Kg) & $136.62^{\mathrm{b}}$ & $152.82^{\mathrm{a}}$ & $154.44^{\mathrm{a}}$ \\
Consumo de alimento acumulado (Kg) & $6.175^{\mathrm{a}}$ & $5.707^{\mathrm{b}}$ & $5.763^{\mathrm{b}}$ \\
Consumo de alimento (g/a/d) & $110.26^{\mathrm{b}}$ & $101.91^{\mathrm{a}}$ & $102.91^{\mathrm{a}}$ \\
Consumo de líquido (l) & $13.36^{\mathrm{b}}$ & $18.89^{\mathrm{a}}$ & $19.07^{\mathrm{a}}$ \\
Consumo de materia seca acumulada (Kg) & $5.619^{\mathrm{b}}$ & $6.423^{\mathrm{a}}$ & $6.483^{\mathrm{a}}$ \\
Conversión alimenticia acumulada & $2.46^{\mathrm{b}}$ & $2.06^{\mathrm{a}}$ & $2.03^{\mathrm{a}}$ \\
Espesor de cáscara & $1.09^{\mathrm{a}}$ & $1.09^{\mathrm{a}}$ & $1.09^{\mathrm{a}}$ \\
Calidad interna del huevo (Unidades Haugh) & $77.97^{\mathrm{a}}$ & $80.70^{\mathrm{a}}$ & $81.20^{\mathrm{a}}$ \\
Pigmentación de yema (unidades) & $8.16^{\mathrm{a}}$ & $8.11^{\mathrm{a}}$ & $8.11^{\mathrm{a}}$ \\
Retribución económica por Kg de Huevo (S/.) & 1.14 & 1.56 & 1.43 \\
\hline
\end{tabular}

a Letras iguales dentro de una misma fila indica que no hay diferencias significativas a la Prueba de Duncan 
En relación al consumo de alimento, los tratamientos con suero de leche (suero y suero más desinfectante) fueron significativamente menores en comparación al tratamiento de agua mas desinfectante. Estos resultados concuerdan con lo obtenido por Vega (1995) en pavos. Contrariamente, las gallinas que recibieron suero de leche tuvieron un consumo de líquidos significativamente mayor en comparación a los que recibieron agua de bebida. Considerando tanto el consumo de alimento como el consumo de líquidos se obtuvo que las gallinas que recibieron suero de leche tuvieron un consumo de materia seca acumulada significativamente mayor que las aves que bebieron agua más amonio cuaternario.

El comportamiento del consumo acumulado de alimento guarda relación inversa con la ingestión de bebidas con suero, una mayor ingestión de suero posibilita un menor consumo de concentrado. La regulación del consumo de alimento en los tratamientos con suero puede ser atribuida al aporte de nutrientes del suero de leche en especial proteínas (De Wit, 1998 y Porter, 1981); quienes indican además, una retención de nitrógeno y un buen valor biológico de sus proteínas.

Del análisis de la Tabla 4 se puede apreciar que los tratamientos con suero y suero más desinfectante presentaron una mayor ingestión de nutrientes y esto está relacionado con la mayor ingestión de suero. En cuanto a la ingestión de materia seca total por tratamiento, esta fue mayor en las gallinas que recibieron suero de leche en comparación al tratamiento control.

Tabla 4. Ingestión Estimada de Nutrientes.

\begin{tabular}{cccc}
\hline Parámetros & $\begin{array}{c}\text { T-1: Agua }+ \\
\text { desinfectante }\end{array}$ & $\begin{array}{c}\text { T-2: Suero de } \\
\text { Leche }\end{array}$ & $\begin{array}{c}\text { T-3: Suero de Leche }+ \\
\text { desinfectante }\end{array}$ \\
\hline Materia Seca (g/ave/día) & $\mathbf{1 0 0 . 3 5}$ & $\mathbf{1 1 4 . 6 9}$ & $\mathbf{1 1 5 . 7 6}$ \\
Proteína Total (g/ave/día) & 18.62 & 19.23 & 19.41 \\
Calcio (g/ave/día) & 3.97 & 6.94 & 7.00 \\
Fósforo(g/ave/día) & 0.308 & 2.82 & 2.87 \\
\hline
\end{tabular}

Al evaluar la ingestión de proteína observamos que los tratamientos con suero de leche (suero y suero más desinfectante) presentaron un mayor consumo de proteínas (19.23 y $19.41 \mathrm{~g} / \mathrm{ave} /$ día) en comparación al tratamiento control (18.62 g/ave/día).

La conversión alimenticia acumulada fue significativamente mejor en los tratamientos con suero de leche en comparación al tratamiento con agua como bebida. En general, la ingestión promedio de suero como bebida mejoro significativamente la conversión alimenticia. La mejor conversión alimenticia en los tratamientos con suero se debe al menor consumo de alimento como consecuencia de un mayor consumo de suero de leche. La menor conversión alimenticia obtenida en los tratamientos con suero, se debería a la elevada ingestión de suero y su consecuente aporte de materia seca en la conversión alimenticia. La conversión alimenticia frente a la adición de amonio cuaternario no se vio afectada estadísticamente y estos resultados concuerdan con estudios realizados por Vega (1995), quien evaluó la utilización del suero líquido de leche y un yodóforo en pavos de carne y del mismo modo la adición del yodóforo no afecto estadísticamente la conversión alimenticia.

Si bien se observa una mayor ingestión de calcio en las gallinas de los tratamientos con suero (Tabla 4), no hubo diferencias en el grosor de la cáscara, medido a través del peso específico del huevo, entre los tratamientos.

En relación a la calidad del albumen del huevo, medido en Unidades Haugh, no se hallaron diferencias entre tratamientos. Sin embargo, las aves que recibieron suero tuvieron una calidad de albumen ligeramente superior, esto se debería posiblemente a la mayor ingestión de fósforo (Tabla 4) y a su influencia de este mineral en la consistencia del albumen denso como lo manifiesta Buxadé (1987), quien señala que un mayor nivel de fósforo de la dieta mejora la calidad del albumen.

Al evaluar las tonalidades del color de yema se pudo apreciar que no presentan diferencias estadísticas, siendo sus puntajes muy similares. No se registraron diferencias dado que el suero de leche carece de pigmentantes que puedan influir en la pigmentación de la yema.

La adición de amonio cuaternario en el suero de leche no afectó estadísticamente en ninguno de los parámetros evaluados; sin embargo, puede desempeñar un papel en la conservación del suero retardando la fermentación láctica y la acción de efectos de origen microbianos como olores y sabores anormales producido cuando determinados microorganismos crecen hasta un limite que sus productos metabólicos llegan a ser detectables, siendo el suero por procedencia muy propicio para ello .

La mayor retribución económica del alimento se obtuvo en el tratamiento con suero de leche, seguido por el tratamiento de suero de leche más amonio cuaternario. Esta mayor retribución económica en los tratamientos con suero se debe a la mayor producción de huevos y al menor consumo de alimento, como consecuencia del importante aporte de nutrientes por parte del suero. 


\section{Conclusiones}

Bajo las condiciones del presente estudio, los tratamientos con suero de leche (T2 y T3) exhibieron mejor comportamiento productivo que el tratamiento con agua de bebida (T1). La mayor retribución económica se obtuvo con el tratamiento con suero de leche (T2).

\section{Literatura citada}

Buxadé, C. 1987. La Gallina Ponedora. Sistemas de Explotación y Técnicas de Producción. Ediciones MundiPrensa. Madrid, España. 519 p.

De Wit, J.N. 1998. Nutritional and Functional Characteristics of Whey Proteins in Food Products. J. Dairy Sci. 81: 597-608.

Espinoza, T. 1993. Evaluación del Suero de Leche en la Alimentación de inicio y crecimiento de Pavos Hybrid. Tesis Ing. Zootecnista. UNALM. Lima, Perú.

Glass, L. y Hedrick, T.I. 1977. Nutritional Composition of Sweet and Acid-type dry wheys. Journal of Dairy Science. 60: 185-192.

Molina, F. Machado, W., Marquetti, F. y Quaia, E. 2013. Toxicidad del amonio cuaternario para microorganismos utilizados en el tratamiento biológico anaeróbico de efluentes. Avance Agroindustrial 34(3): 35-37.

Kermanshahi, H. y Rostami, H. 2006. Influence of Supplemental Dried Whey on Broiler Performance and Cecal Flora. International. Journal of Poultry Science. 6: 538-543.

Kosikowski, F. 1979. Whey Utilization and Whey Products. Journal of Dairy Science. 62: 1149-1160.

Porter. J. 1981. Leche y Productos Lácteos. Editorial Acribia S.A. Zaragoza, España.

Ribas, O.B. 2010. Biocidas: Datos sobre su evaluación para la salud, industria alimentaria e impacto ambiental. Anales de la Real Academia de Farmacia. Monografía XXXI: Aspectos higiénicos de los alimentos microbiológicamente seguros. Madrid - España.

Torki, M. y Molanapour, B. 2005. Effect of Dried Whey and Probiotic Supplementation on Growth Performance in Broilers. 15 th . European Symposium on Poultry Nutrition. World Poultry Science Association.

Torres-Rodriguez, A., Higgins, S., Vicente, L. , Wolfenden, A., Ganna-Ramirez, G., Barton, J., Donoghue, A. y Hargis, B. 2007. Effect of Lactose as a Prebiotic on Turkey Body weight under comercial conditions. Journal Applied Poultry Research. 16: 635641.

Trauth, E., Lemaitre, J.P., Rojas, C., Divies, C. y Cachon, R. 2001. Resistance of Immobilized Lactic Acid Bacteria to the inhibitory effect of quaternary ammonium sanitizers. LWT Food Science and Technology 34 (4): 235-243.

Valencia, E. y Ramirez, M. 2009. La industria de la leche y la contaminación del agua. Elementos 73:27 - 31 .
Varnan, A.H. y Sutherland, J. P. 1996. Leche y productos lácteos. Editorial Acribia S.A. Zaragoza, España.

Vega, A. 1995. Utilización del Suero líquido de Leche y un desinfectante yodóforo en el engorde y acabado de Pavos. Tesis Ingeniero Zootecnista. UNALM. Lima, Perú. 